\title{
Hydrometeorological Hazards: Monitoring, Forecasting, Risk Assessment, and Socioeconomic Responses
}

\author{
Huan Wu, ${ }^{1,2}$ Maoyi Huang, ${ }^{3}$ Qiuhong Tang, ${ }^{4}$ Dalia B. Kirschbaum, ${ }^{2}$ and Philip Ward ${ }^{5}$ \\ ${ }^{1}$ University of Maryland, College Park, MD, USA \\ ${ }^{2}$ NASA Goddard Space Flight Center, Greenbelt, MD, USA \\ ${ }^{3}$ Pacific Northwest National Laboratory, Richland, WA, USA \\ ${ }^{4}$ Key Laboratory of Water Cycle and Related Land Surface Processes, Institute of Geographic Sciences and \\ Natural Resources Research, Chinese Academy of Sciences, Beijing, China \\ ${ }^{5}$ Vrije Universiteit, Amsterdam, Netherlands \\ Correspondence should be addressed to Huan Wu; huanwu@umd.edu
}

Received 1 August 2016; Accepted 1 August 2016

Copyright (C) 2016 Huan Wu et al. This is an open access article distributed under the Creative Commons Attribution License, which permits unrestricted use, distribution, and reproduction in any medium, provided the original work is properly cited.

Hydrometeorological hazards are caused by extreme meteorological and climate events, such as floods, droughts, hurricanes, tornadoes, or landslides. They account for a dominant fraction of natural hazards and occur in all regions of the world, although the frequency and intensity of certain hazards and society's vulnerability to them differ between regions. Severe storms, strong winds, floods, and droughts develop at different spatial and temporal scales, but all can become disasters that cause significant infrastructure damage and claim hundreds of thousands of lives annually worldwide. Oftentimes, multiple hazards can occur simultaneously or trigger cascading impacts from one extreme weather event. For example, in addition to causing injuries, deaths, and material damage, a tropical storm can also result in flooding and mudslides, which can disrupt water purification and sewage disposal systems, cause overflow of toxic wastes, and increase propagation of mosquito-borne diseases.

Particularly, floods and landslides caused more than $55 \%(2,000)$ of a total of 3,600 significant natural disasters worldwide during 2002-2011 [1], killing over 65,000 people and affecting over 1.1 billion people with an estimated cost of $\$ 280$ billion (US dollars in 2011). The risks of flooding to population and infrastructure are continuing to increase due to the acceleration of the global water cycle [2] and rapid population growth. At the same time, populations and economic activities in floodplains around the world are growing rapidly, leading to a rapid increase in our socioeconomic exposure to floods $[3,4]$. Monitoring and forecasting of the occurrence, intensity, and evolution of hydrometeorological extreme events have been critical components for a variety of humanitarian and government agencies in their efforts to prepare, mitigate, and manage responses to disaster, aiming at saving lives and limiting damage. Satellite remote sensing offers new opportunities to pursue flood estimation from regional to global scales, providing information of changes in surface water dynamics through direct observations using optical (e.g., $[5,6])$ or Synthetic Aperture Radar (SAR) imagery (e.g., [7, 8]) and hydrological modeling with remote sensed information inputs such as precipitation, land cover, vegetation, topography, and hydrography (e.g., [911]). However, one of the major challenges faced by the flood community is the lack of ground truth data for validating or quantifying the uncertainty of historic and ongoing flooding events estimated by existing flood monitoring and forecasting systems, for example, the Dartmouth Flood Observatory (DFO, http://floodobservatory.colorado.edu/, [5]), NASA Near Real Time Global MODIS Flood Mapping (http://oas.gsfc.nasa.gov/floodmap/), the Global Flood Monitoring System (GFMS, http://flood.umd.edu/, [10, 11]), and Global Flood Awareness System (GloFAS, http://www.globalfloods.eu/, [12]).

As a direct example, Figure 1 shows an example of how satellite precipitation can be used to drive a global hydrological model in terms of providing timely and relatively 


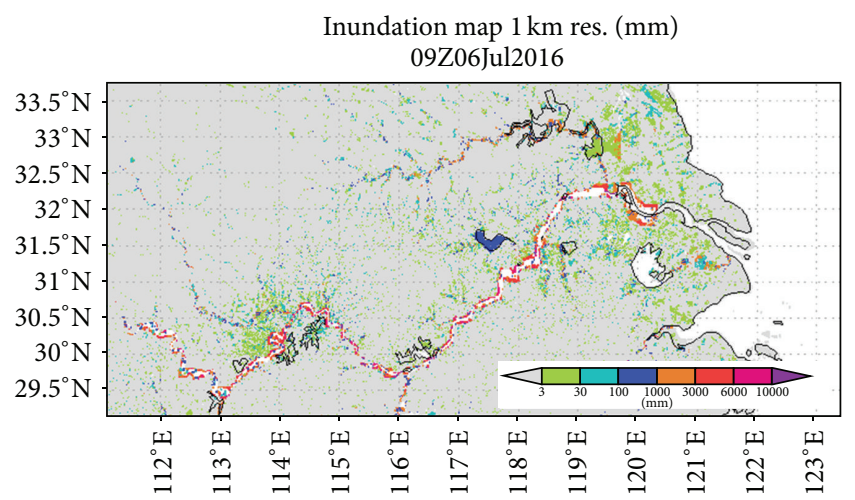

FIGURE 1: The GFMS calculated inundation map at $1 \mathrm{~km}$ resolution for the Yangtze River basin on July 6, 2016. More inundation maps and other data are available at http://flood.umd.edu/.

detailed flood information at $1 \mathrm{~km}$ resolution. Figure 1 shows results of the Global Flood Monitoring System (GFMS) for a widespread flooding situation that occurred in south China in July 2016. However, validation of such real time numerical model calculated flood information is challenging because of the availability of ground-based information. The comparison and integration of both model and remote sensing based flood information is vital to enhancing of the value of the flood information for better application by various users.

The papers collected in this special issue cover a wide range of research topics related to floods and landslides and shed light on some of recent progresses and ongoing researches in the field. In this special issue, G. J.-P. Schumann and K. M. Andreadis presented a method to infer the impact of a better Digital Elevation Model (DEM) on the prediction of flood risk over the Lower Zambezi basin in terms of the DEM's contribution to the overall accuracy of flood prediction. Their results highlight the notion that having higher resolution measurements would improve large-scale flood inundation prediction capabilities in the Lower Zambezi by at least $30 \%$ and significantly reduce the number of people affected as well as the economic loss associated with high magnitude flooding. The procedure developed by them is straightforward and has the potential to be applied to other regions where high quality topographic and hydrodynamic data are currently unavailable as in many cases of GFMS.

Remote controlled boats equipped with an Acoustic Doppler Current Profiler (ADCP) can be extremely valuable for obtaining flood information, for example, water discharge and velocity profile for ongoing flood events, as an important complementary tool to satellite and air based sensors. They have advantages of high productivity, fast measurements, operator safety, and high accuracy. J. Lee et al. developed the methods for better controlling and operating a remote boat in the rapid flow condition during flood events and successfully achieved high accuracy discharge measurement through the distance made good (DMG) modification of the boat path.
A reliable historic flood event archive will have great value in many cases for both science and applications, and therefore it is on the top of the wish list of many hydrologists, along with accurate DEM and precipitation datasets. W. T. L. Chow et al. developed a multimethod approach combining station precipitation data with archival newspaper and governmental records into a comprehensive local flood inventory, in which changes in flash floods frequencies and reported impacts of floods towards Singapore society were well documented. W. T. L. Chow et al. assessed that Singapore has relatively lower vulnerability to floods than other regional cities due to consistent and successful infrastructural development, widespread flood monitoring, and effective advisory platforms. However, the flood inventory they created indicated significant increases in reported flash flood frequency occurred in contemporary (post-2000) relative to historic (1984-1999) periods and storms in recent years are more intense and frequent, which indicates a future with increasing vulnerabilities. Such flood inventory not only formed the fundamental database for investigation of flooding patterns in Singapore, but also can be a local reference or complementary for the global flood inventory compiled by DFO which has showed great values in global flood model validation $[10,11]$ and other applications. To demonstrate and assess the new features and trends of flood risk in urbanized areas, it is also important to reasonably define the flood threshold with consideration of damage. C. Li et al. proposed S-shaped function of return period and damage which is tested in the Taihu River basin and can be utilized for timely and effective flood damage assessment and prediction. Several global scale flood risk models are now also available for assessing the impacts of floods on people and societies (e.g., [3, 13-18]), and they also have the same needs of high quality data for model validation [19].

Y. Park et al. proposed an urban landslide vulnerability assessment methodology considering urban social and economic aspects, based on the landslide susceptibility maps that the Korean Forest Service utilizes to identify landslide source areas. The physical and socioeconomic vulnerability levels analysis for Seoul, Korea, using the method indicates that the higher population density areas located downstream of mountainous areas tend to be more vulnerable than the areas in opposite conditions.

This special issue does not feign to address all challenges in monitoring and modeling of hydrometeorological hazards, however. Rather, we hope it serves as valuable asset for the physical and social scientists who work on topics related to hydrometeorological hazards in finding means to integrate modeling and remote sensing approaches that are complementary to each other for providing accurate forecasts, issuing timely warnings, monitoring ongoing hazards, reducing vulnerabilities, and building resilience for future.

\section{Acknowledgments}

We thank all the authors who contributed to this issue and all the reviewers who provide valuable, constructive comments 
to the manuscripts and help to improve the quality of these papers published in this issue.

\section{Huan Wu Maoyi Huang Qiuhong Tang \\ Dalia B. Kirschbaum Philip Ward}

\section{References}

[1] World Disasters Report, International Federation of Red Cross and Red Crescent Societies, 2012.

[2] P. J. Webster, G. J. Holland, J. A. Curry, and H.-R. Chang, "Changes in tropical cyclone number, duration, and intensity in a warming environment," Science, vol. 309, no. 5742, pp. 18441846, 2005.

[3] Y. Hirabayashi, R. Mahendran, S. Koirala et al., "Global flood risk under climate change," Nature Climate Change, vol. 3, no. 9, pp. 816-821, 2013.

[4] H. C. Winsemius, J. Aerts, L. van Beek et al., "Global drivers of future river flood risk," Nature Climate Change, vol. 6, no. 4, pp. 381-385, 2015.

[5] R. Brakenridge and E. Anderson, "MODIS-based flood detection, mapping and measurement: the potential for operational hydrological applications," in Transboundary Floods: Reducing Risks Through Flood Management, J. Marsalek, G. Stancalie, and G. Balint, Eds., vol. 72 of Nato Science Series: IV: Earth and Environmental Sciences, pp. 1-12, Springer, New York, NY, USA, 2006.

[6] C. Ordoyne and M. A. Friedl, "Using MODIS data to characterize seasonal inundation patterns in the Florida Everglades," Remote Sensing of Environment, vol. 112, no. 11, pp. 4107-4119, 2008.

[7] M. S. Horritt, D. C. Mason, D. M. Cobby, I. J. Davenport, and P. D. Bates, "Waterline mapping in flooded vegetation from airborne SAR imagery," Remote Sensing of Environment, vol. 85, no. 3, pp. 271-281, 2003.

[8] D. C. Mason, I. J. Davenport, J. C. Neal, G. J.-P. Schumann, and P. D. Bates, "Near real-time flood detection in urban and rural areas using high-resolution synthetic aperture radar images," IEEE Transactions on Geoscience and Remote Sensing, vol. 50, no. 8, pp. 3041-3052, 2012.

[9] M. S. Shrestha, G. A. Artan, S. R. Bajracharya, and R. R. Sharma, "Using satellite-based rainfall estimates for streamflow modelling: Bagmati Basin," Journal of Flood Risk Management, vol. 1, no. 2, pp. 89-99, 2008.

[10] H. Wu, R. F. Adler, Y. Hong, Y. Tian, and F. Policelli, "Evaluation of global flood detection using satellite-based rainfall and a hydrologic model," Journal of Hydrometeorology, vol. 13, no. 4, pp. 1268-1284, 2012.

[11] H. Wu, R. F. Adler, Y. Tian, G. J. Huffman, H. Li, and J. Wang, "Real-time global flood estimation using satellite-based precipitation and a coupled land surface and routing model," Water Resources Research, vol. 50, no. 3, pp. 2693-2717, 2014.

[12] L. Alfieri, P. Burek, E. Dutra et al., "GloFAS-global ensemble streamflow forecasting and flood early warning," Hydrology and Earth System Sciences, vol. 17, no. 3, pp. 1161-1175, 2013.

[13] N. W. Arnell and S. N. Gosling, "The impacts of climate change on river flood risk at the global scale," Climatic Change, vol. 134, no. 3, pp. 387-401, 2016.
[14] CIMA Foundation, Improvement of the Global Flood Model for the GAR15. Background Paper prepared for the 2015 Global Assessment Report on Disaster Risk Reduction, UNISDR, Geneva, Switzerland, 2015.

[15] F. Dottori, P. Salamon, A. Bianchi, L. Alfieri, F. A. Hirpa, and L. Feyen, "Development and evaluation of a framework for global flood hazard mapping," Advances in Water Resources, vol. 94, pp. 87-102, 2016.

[16] C. C. Sampson, A. M. Smith, P. B. Bates, J. C. Neal, L. Alfieri, and J. E. Freer, "A high-resolution global flood hazard model," Water Resources Research, vol. 51, no. 9, pp. 7358-7381, 2015.

[17] P. J. Ward, B. Jongman, F. S. Weiland et al., "Assessing flood risk at the global scale: model setup, results, and sensitivity," Environmental Research Letters, vol. 8, no. 4, Article ID 044019, 2013.

[18] H. C. Winsemius, L. P. H. Van Beek, B. Jongman, P. J. Ward, and A. Bouwman, "A framework for global river flood risk assessments," Hydrology and Earth System Sciences, vol. 17, no. 5, pp. 1871-1892, 2013.

[19] P. J. Ward, B. Jongman, P. Salamon et al., "Usefulness and limitations of global flood risk models," Nature Climate Change, vol. 5, no. 8, pp. 712-715, 2015. 

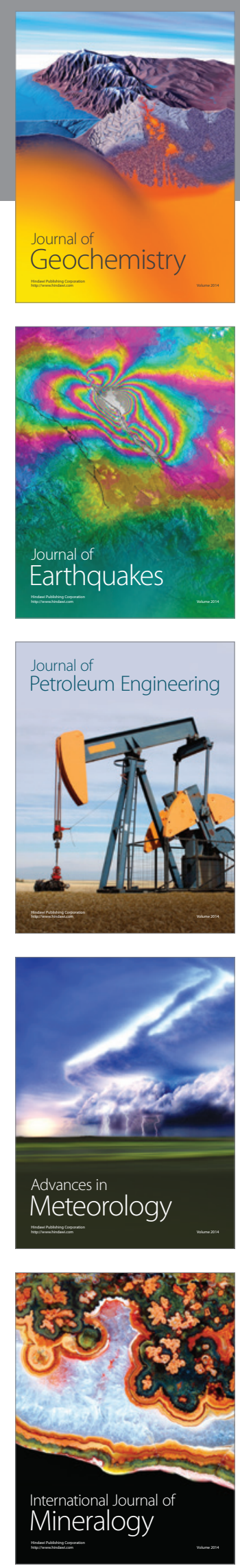
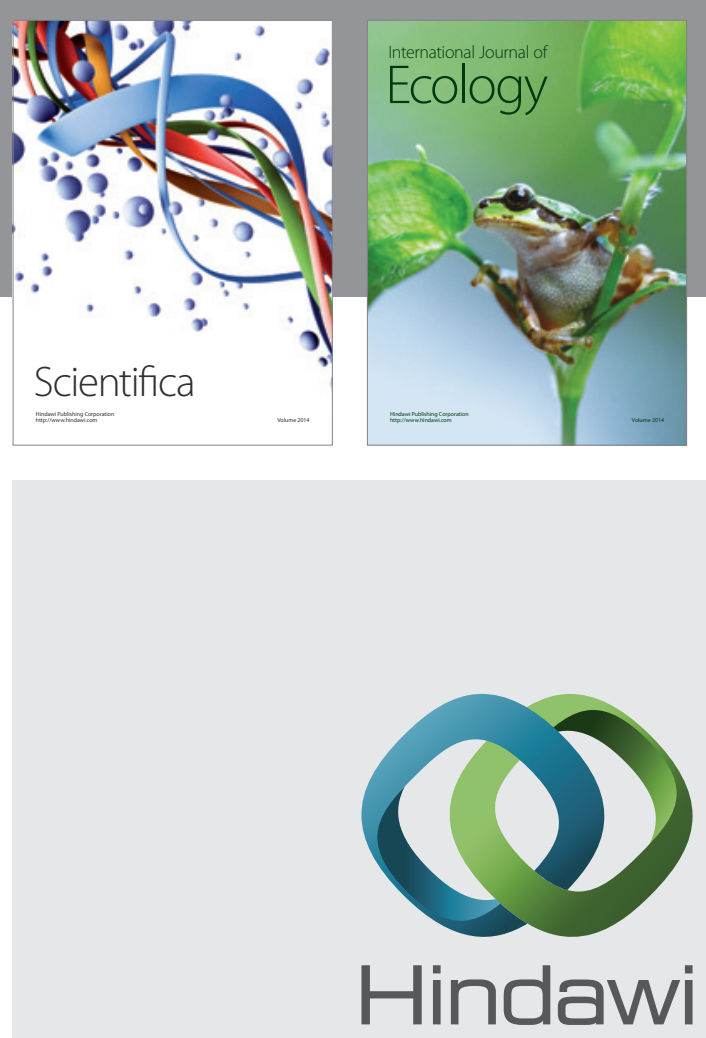

Submit your manuscripts at

http://www.hindawi.com
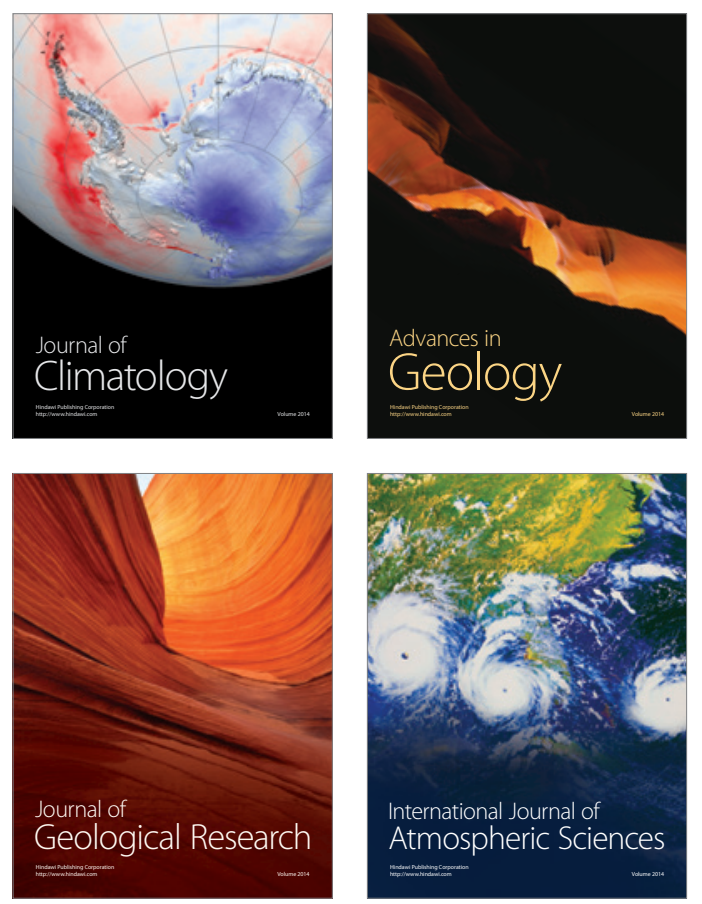

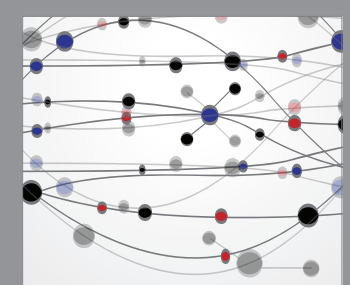

The Scientific

\section{World Journal}
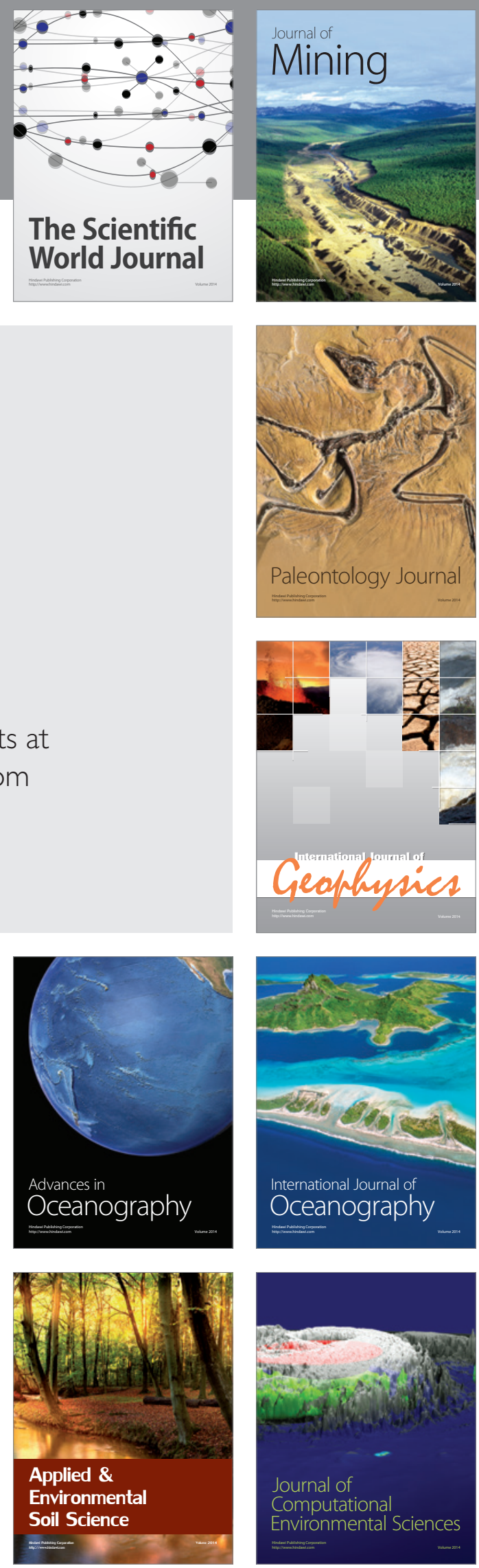